\title{
Perencanaan Angkutan Umum Perkotaan Berkelanjutan
}

\author{
Ahmad Munawar
}

The realization of public transportation in cities in Indonesia has some obstacles. The problems cover services because of high operational cost, the decrease of passengers, and the safety in public transportation. The weakness of public transportation also grows the informal sectors in this sector. The comparative analysis regarding public transportation between Yogyakarta and Bandung including net way, vehicles, headway, load factor, the quality and the obstacle. Hence, to build cities public transportation either in short, middle and long term. Theses terms cover the sustainability, buy service system, and massive public transportation system.

Kata kunci: angkutan umum, berkelanjutan, sektor informal

$\mathrm{M}$ asalah transportasi yang terjadi di daerah perkotaan Indonesia adalah bagaimana memenuhi permintaan jumlah perjalanan yang semakin meningkat, yang tidak menimbulkan kemacetan arus lalulintas di jalan raya. Masalahnya tidak hanya pada kemacetan lalulintas, tetapi juga pada perencanaan regional. Ini memerlukan suatu penanganan yang menyeluruh.

Kalau dilihat dari perkembangan transportasi perkotaan yang ada, terlepas dari krisis ekonomi yang melibatkan Indonesia sejak tahun 1997, mobil pribadi tetap merupakan moda transportasi yang dominan, baik untuk daerah urban maupun sub urban. Populasi pergerakan mobil pribadi yang begitu besar di daerah perkotaan ditambah dengan pola angkutan umum yang masih tradisional, menimbulkan biaya sosial yang sangat besar akibat waktu tempuh yang terbuang percuma, pemborosan bahan bakar minyak, depresi kendaraan yang terlalu cepat, kecelakaan lalulintas, hilangnya opportunity cost, timbulnya stress, meningkatnya polusi udara, dan kebisingan. Hal ini sejalan dengan pembangunan ekonomi dan makin bertumbuhnya jumlah masyarakat golongan menengah dan menengah atas didaerah perkotaan, yang terjadi jauh sebelum krisis. Kenyamanan, keamanan, privacy, fleksibilitas pergerakan dan prestise merupakan faktor-faktor utama yang menyebabkan kendaraan pribadi tetap memiliki keunggulan sebagai moda transportasi, khususnya di daerah urban. Sementara itu "sistem angkutan umum massal" (SAUM) yang modern sebagai bagian integral dari ketahanan daya dukung kota (city survival) masih dalam tahap rancangan dan perencanaan serta belum berada didalam alur utama (mainstream) kebijakan dan keputusan pemerintah dalam rangka menciptakan sistem transportasi kota yang berimbang, efisien dan 
berkualitas. Belum terciptanya SAUM modem sebagai atribut menuju kota "metropolitan" dan oleh karenanya belum merupakan alternatif yang patut diperhitungkan bagi pembuat perjalanan merupakan pembenaran dari pemakaian kendaraan pribadi okupansi rendah yang tidak efisien. Oleh karena selama beberapa dekade belakangan ini tidak ada langkah "terobosan" yang berarti, maka antrian dan kemacetan lalulintas yang berkepanjangan pada setiap koridor dan pusat kota. Sebagai akibatnya pemborosan besar-besaran dari energi BBM serta polusi udara akan terus menjadi menu sehari-hari bagi mereka yang melakukan perjalanan di perkotaan (urban trip makers). Yogyakarta yang mempunyai daya tarik wisata yang cukup tinggi akan menyebabkan banyaknya pengunjung di pusat-pusat wisata dan pusat kota (Malioboro) yang menguntungkan dari segi perekonomian, tetapi perlu difasilitasi dengan sarana prasarana yang memadai, termasuk sistem transportasi yang andal. Di sisi lain, Yogyakarta akan tetap dibanjiri oleh penduduk pendatang karena daya tariknya sebagai kota pendidikan. Resultante dari semua itu adalah bahwa kota menjadi tempat dengan pergerakan orang dan kendaraan makin menjadi sulit dan mahal. Biaya sosial akan menjadi bagian yang dominan dari biaya perjalanan perkotaan (urban travel disutility), padahal "externalities" dan "intangibles" yang lainnya tidak pernah diperhitungkan didalam proses perencanaan dan manajemen transportasi kota. Ketidakberdayaan kota bukan lagi "economic assets" akan tetapi justru menjadi "economic liability". Dipandang dari sisi rasio jalan dengan lahan kota, memang masih perlu membangun jaringan jalan baru, termasuk jembatan layang, namun membangun jaringan jalan kota termasuk jalan bebas hambatan di tengah-tengah kota bukan saja sangat mahal karena langka dan mahalnya lahan, tetapi juga tidak akan menghilangkan kemacetan masif oleh karena adanya cadangan lalulintas kendaraan yang terbangkitkan (reservoir of traffic) yang selalu siap menunggu dan mengisi setiap jengkal kapasitas ruang jalan yang diberikan oleh fasilitas baru tersebut dan dalam waktu singkat membuat kemacetan baru. Perencanaan dan kebijakan transportasi kota oleh karenanya harus berubah, yakni dari pendekatan membangun sistem prasarana (supply side) menjadi pendekatan manajemen dan efisiensi sistem (demand side). Paradigma baru ini berpegang kepada prinsip manajemen sistem transportasi (MST) dan bertujuan mencari keseimbangan antara sistem angkutan umum yang mewakili pergerakan manusia di kota dengan sistem jalan raya yang mewakili pergerakan kendaraan pribadi. Artinya, selain sistem jaringan jalan kota yang memadai bagi pergerakan angkutan pribadi, kota yang efisien juga harus mampu menyediakan sistem angkutan massal yang secara efisien dan handal mampu melakukan angkutan orang dalam jumlah besar dan dalam waktu yang relatif singkat.

Kesemuanya ini memang memertukan suatu kebijakan yang dapat mendukung perkembangan angkutan umum perkotaan. Akan tetapi, dampak sosial dan budaya dari kebijakan tersebut perlu dipernitungkan. Sosialisasi kepada masyarakat perlu dilakukan secara terus-menerus. Aspirasi dari setiap unsur masyarakat perlu didengar. Dampak negatif dari setiap rencana kebijakan harus diminimalkan, bahkan kalau dapat tanpa menimbulkan dampak negatif. Kebijakan angkutan umum harus mengakomodir aspirasi dari operator-operator angkutan umum yang ada. Mereka harus dilibatkan secara aktif dalam pengambilan keputusan. 


\section{Permasalahan Angkutan Umum Perkotaan di Indonesia}

Penyelenggaraan angkutan umum (bus) perkotaan di Indonesia penuh dengan permasalahan. Beberapa masalah utama yaitu:

1. - rendahnya kualitas dan pilihan

2. penyebab kerriacetan dan kecelakaan karena disiplin pengemudi yang rendah

3. tidak cukupnya dana untuk memperbarui dan memperbaiki kendaraan

4. pengaturan pemberhentian dan naik turun penumpang oleh preman.

5. kurang aman (banyak copet)

6. kompleksitas dan kekakuan aturan yang ada saat ini

7. struktur administrasi dan manajemen yang kurang efektif

8. kepemilikan kendaraan secara pribadi sehingga tidak dapat diatur dalam satu kesatuan

Seharusnya bus perkotaan memberikan pelbagai pilihan altermatif kualitas pelayanan yang disesuaikan dengan permintaan. Saat ini sebagian besar penumpang angkutan umum hanyalah golongan menengah ke bawah, yang tidak mempunyai pilihan lain selain menggunakan angkutan umum (captive passenger). Umumnya kenyamanan dan kualitas bus perkotaan sangat rendah, kursi-kursi sudah banyak yang rusak, interior dalam sudah bobrok, ban sudah gundul serta sering mogok. Ditambah lagi dengan banyaknya copet di dalamnya. Para penumpangnya harus sudah siap dengan pelbagai kondisi angkutan umum seperti tersebut di atas. Oleh karena itu, mereka yang mempunyai sepeda motor, mobil atau dapat menggunakan taksi akan. jarang menggunakan angkutan umum. Mereka yang tidak mempunyai pilihan lain selain angkutan umumpun mempunyai cita-cita agar dapat membeli kendaraan pribadi (mobil atau motor) agar tidak tergantung lagi ke angkutan umum. Dikhawatirkan, jika ini dibiarkan, maka keberadaan bus perkotaan akan sangat dikhawatirkan kelanjutannya. Secara perlahan-lahan, eksistènsi bus perkotaan akan semakin pudar, diganti oleh tumbuhnya kendaraan -pribadi, motor maupun mobil, yang akan mendominasi jalan raya dan menyebabkan kemacetan di jalanjalan.

Di pelbagai kota besar di Indonesia, seperti Jakarta, Bandung maupun Yogyakarta, bus perkotaan dikontrol oleh preman. Mereka mengatur jadual keberangkatan di halte-halte. Di dalam kampus UGM, sopir pocokan menggantikan sopir yang asli mengitari kampus UGM, sedangkan sopir yang asli beristirahat di warung pinggir jalan. Sedangkan di sepanjang jalan, para calo siap ikut menawarkan calon penumpang untuk masuk ke dalam bus, dengan imbalan tertentu.

Krisis moneter yang dialami Indonesia baru-baru ini sangat mempengaruhi kinerja bus perkotaan. Kenaikan suku cadang yang melambung tinggi menyebabkan biaya pemeliharaan kendaraan menjadi meningkat tajam. Dengan kemampuan daya beli masyarakat yang rendah, maka kenaikan tarif yang tinggi tidak dimungkinkan, karena akan mempengaruhi demand yang ada. Ini menyebabkan pelayanan angkutan umum menjadi semakin rendah, kualitas kendaraan menjadi semakin buruk. Guna perbaikan kendaraan, dilakukan kanibalisme, yaitu -menggerogoti onderdil kendaraan yang sudah rusak berat, untuk dipasang pada kendaraan yang masih lebih baik. Tentu saja kendaraan yang rusak berat dibiarkan semakin rusak dan tidak mungkin beroperasi lagi. 
Tidak ada proses perencanaan perubahan jaringan trayek yang sistematis. Jika ada perubahan permintaan, misalnya perkembangan pemukiman-pemukiman baru, tidak segera diantisipasi dengan pengembangan trayek baru. Jaringan trayek tidak berubah dalam waktu yang lama. Hal ini memiliki konsekuensi-konsekuensi:

1. karena layanan angkutan umum tidak sesuai dengan permintaan, cara-cara informal telah berkembang untuk mengisi kesenjangan tersebut. Sebagai contoh, ojek yang tidak mempunyai ijin resmi menarik penumpang dalam jumlah yang banyak di malam hari dan di jalan-jalan kecil.

2. karena pemerintah kurang aktif dalam perencanaan dan pengaturan angkutan umum, cara-cara informal semakin berkembang, 'kekosongan peraturan' telah memberikan kesempatan bagi kelompok informal untuk mengontrol pengoperasian angkutan umum. Setiap jenis angkutan, seperti angkutan umum resmi yang mempunyai ijin, kendaraan umum plathitam, ojek, becak dan andong diorganisir oleh suatu kelompok, dalam satu trayek atau daerah. Kelompokkelompok ini telah menyepakati batasbatas wilayah mereka dan dapat menggerakkan sejumlah besar orang untuk mempertahankan trayek atau kawasan mereka. Dengan demikian kota terbagi ke dalam potongan teritorial kecil-kecil untuk setiap jenis trayek angkutan. Masing-masing merasa menguasai daerahnya, karena alasan historis. Angkutan umum menjadi monopoli pemilik daerah kekuasaan tersebut.

Organisasi-organisasi informal kemungkinan dapat menjadi gangguan bagi pemerintah guna pengawasan pada tiap jenis kendaraan yang beroperasi di suatu trayek atau daerah. Suatu kebijakan lalu lintas dan angkutan perkotaan yang saling terkait diperlukan yang akan mengelola sistem angkutan kota sebagai satu kesatuan. Kebijakan tersebut harus mencerminkan kebutuhan semua pengguna jalan, dan mengalokasikan tata ruang jalan diantara para pengguna atas dasar prioritas kepentingan. Sangat penting bahwa kelompok-kelompok informal dilibatkan penuh dalam proses pembaruan dan diyakinkan bahwa pengoperasian angkutan umum yang lebih efisien, dinamis dan sesuai dengan permintaan, bebas dari hambatan praktis juga menampung keinginan mereka.

\section{Kinerja Angkutan Umum: Studi Kasus di Yogyakarta dan Bandung}

Kinerja angkutan umum di dua kota, Yogyakarta dan Bandung dianalisis sebagai referensi. Kedua kota tersebut mempunyai karakteristik demand angkutan umum yang berbeda. Dari perbandingan yang dilakukan oleh Departemen Perhubungan (1999), pengguna angkutan .umum di Bandung sangat tinggi, yaitu sebesar $73 \%$ dari seluruh perjalanan di perkotaan, dibandingkan dengan di Yogyakarta yang hanya sebesar $28 \%$.

Trayek angkutan umum yang melayani wilayah perkotaan di Yogyakarta terdiri dari 16 trayek, yang terdiri dari jalur 1 sampai dengan jalur 19 , dengan 3 trayek yang tidak aktif, yaitu jalur 8,13 dan 18 . Panjang trayek bervariasi, mulai dari $25 \mathrm{~km}$ sampai $62 \mathrm{~km}$. Jumlah kendaraan seluruhnya 591 armada, yang dikelola oleh 5 koperasi. Sebagian besar armada berupa bus, dengan kapasitas tempat duduk sebesar 24 penumpang. Dengan jumlah armada sedemikian banyak, maka waktu antara kedatangan kendaraan (headway) sangat cepat, yaitu berkisar antara 2 sampai 5 menit, sehingga 
penumpang tidak perlu menunggu terlalu lama untuk menaiki bus tersebut. Sebagian besar $(55 \%)$ dari pengguna angkutan umum adalah pelajar/mahasiswa, dan mereka merupakan captive passenger (penumpang yang tidak puny pilihan lain selain menggunakan angkutan umum).. Dari perbandingan hasil survey load factor (tingkat isian) angkutan umum rata-rata di perkotaan Yogyakarta, terjadi penurunan yang sangat drastis. Pada tahun 2000 , load factorrata-rata bus perkotaan di Yogyakarta sebesar. $36 \%$. Jumlah ini menurun menjadi $27 \%$ pada tahun 2004. Berarti rata-rata penumpang bus perkotaan di Yogyakarta saat ini kurang dari sepertiga kapasitasnya. Permasalahan angkutan umum yang lain adalah masalah keamanan. Bus perkotaan yang cukup besar, memungkinkan copetcopet beraksi secara berkelompok.

Trayek angkutan umum perkotaan di Bandung didominasi oleh angkot kecil dengan jumlah tempat duduk untuk 12 penumpang. Jaringan trayek terdiri dari 38 jalur angkot kecil, 11 jalur bus DAMRI dan angkot-angkot informal (plat hitam). Total jumlah angkutan umum perkotaan (formal) di kota Bandung sebanyak 6418 armada. Sering terjadi penyimpangan rute angkot, keluar dari trayek yang seharusnya dijalani. Ada dua hal yang menyebabkan penyimpangan tersebut:

1. untuk menghindari kemacetan

2. untuk menghindari daerah-daerah dengan demand yang kecil, agar segera sampai ke lokasi dengan demand yang lebih besar.

Frekuensi angkot sangat tinggi. Waktu antara kedatangan angkot (headway) ratarata hanya 2,2 menit. Enam trayek mempunyai headway rata-rata dibawah 1 menit, sedangkan 22 trayek mempunyai headway antara 1 sampai 2 menit. Panjang trayek sangat pendek, rata-rata sepanjang
$12 \mathrm{~km}$. Sebagian besar (69\%) penumpang merupakan' penumpang yang tidak mempunyai alternatif lain untuk melakukan perjalanannya (captive passengers). Load factor(tingkat isian) rata-rata angkot cukup tinggi, yaitu $68 \%$. Berbeda dengan di Yogyakarta, dengan daya angkut yang kecil, maka keamanan lebih terjamin. Kendaraan yang kecil ini tidak memberi peluang adanya copet yang beraksi secara berkelompok. Selain angkutan formal, angkutan informal yang berupa ojek sangat populer di Bandung. Jika di Yogyakarta pangkalan ojek kebanyakan hanya diisi oleh kurang dari 10 sepeda motor, di Bandung banyak pangkalan ojek yang diisi oleh lebih dari 10 sepeda motor. Bahkan di Terminal Dago, terdapat 170 sepeda motor ojek. Pada sore/ malam hari, kebanyakan angkot hanya menjalani sebagian dari trayek-trayek yang seharusnya dijalani oleh angkutan umum tersebut, yang mempunyai pangsa pasar yang tinggi. Di trayek-trayek ujung, mereka memutar sebelum sampai ke tujuan akhir trayek. Kekosongan inilah yang diisi oleh pengemudi ojek tersebut. Ojek kemudian sudah di"formal"kan oleh Pemerintah Kota Bandung dengan mengeluarkan Perda tentang ojek.

\section{Sistem Buy the Service}

Suatu alternatif perbaikan bus perkotaan yang saat ini dalam proses pelaksanaan di Yogyakarta adalah dengan merubah manajemen pelayanan bus perkotaan menjadi sistem buy the service. Sistem ini akan merombak secara total system yang ada saat ini, yaitu sistem setoran. Pengelolaan angkutan umum dilakukan secara bersama-sama antara pemerintah dan operator yang ada. Semua pihak yang terkait dengan angkutan umum perkotaan diikut sertakan dalam sistem yang baru tersebut, mulai dari koperasi-koperasi, op- 
erator, crewdan juga mereka yang terlibat secara informal pada bisnis angkutan umum perkotaan ini. Tidakada penambahan jumlah bus perkotaan. Operator bus yang lama diberi kesempatan untuk mengganti menjadi bus yang baru. Biaya penggantian bus akan disubsidi oleh pemerintah. Sebenarnya sebelumnya rencana ini sudah akan dianggarkan oleh DPRD DIY untuk tahun anggaran 2005, tetapi akhimya diputuskan untuk ditunda satu tahun guna sosialisasi. Anggaran ini selain untuk penyediaan bus juga termasuk penyediaan halte-halte di tempat henti yang sudah ditentukan. Busbus dirancang khusus, dengan lantai dasar bus agak tinggi, sehingga penumpang hanya dapat turun di halte saja. Pembelian karcis dilakukan di halte, sehingga sopir tidak memegang uang lagi. Sopir, satpam (untuk menjaga keamanan dalam bus dan halte) serta penjual karcis digaji tetap (mingguan atau bülanan). Crew bus perkotaan ini diambilkan dari crew bus perkotaan yang lama, termasuk mereka yang ikut serta dalam bisnis angkutan umum perkotaan ini secara informal. Standar pelayanan dan jadual perjalanan ditentukan secara tetap oleh badan pengelola, yang terdiri dari unsur pemerintah propinsi, organda dan koperasi angkutan yang ada pada saat ini. Pengelolaan dilakukan secara bersamasama, dengan suatu perjanjian bersama antara pihak-pihak yang mengelola. Jika ada kerugian, maka Pemerintah Propinsi akan menanggung kerugian tersebut dalam bentuk subsidi. Pelayanan diharapkan selama 16 jam, dari pukul 5.00 sampai 21.00 , dengan penempatan crew secara 2 . shift, yaitu shift pertama (pukul $5.00-13.00$ ) dan shift kedua $(13.00-21.00)$. Direncanakan akan disediakan pelbagai tingkat pelayanan bus, mulai dari bus ekonomi, patas sampai patas AC. Perubahan ini akan dilakukan secara berangsur-angsur. Untuk tahun 2006, direncanakan merubah dulu 50 armada bus perkotaan menjadi bus patas $A C$ untuk melayani 3 trayek, yaitu:

1. trayek Prambanan-Adisucipto-Tugu - Malioboro - Kusumanegara Adisucipto-Prambanan pp,

2. trayek Terminal Jombor - Mangkubumi - Malioboro - Gondomanan Gembiraloka - Stasiun Lempuyangan - Kotabaru - Gejayan - Ring Road Utara-Terminal Jombor pp dan

3. trayek Adisucipto - Ring Road Utara Terminal Condong Catur - Jalan Kaliurang - UGM - Diponegoro Malioboro - Ngasem - Pojok Beteng Kulon/Wetan - Kotagede - Janti Adisucipto pp.

Sosialisasi sudah dilakukan kepada para crew angkutan umum perkotaan dan disambut dengan sangat antusias. Sistem ini juga sudah disosialisasikan kepada juru parkir dan pedagang kaki lima. Mereka tidak menolak -sistem tersebut, karena memang tidak akan berpengaruh terhadap pekerjaan mereka.

\section{Penutup}

Untuk jangka pendek, kebijakan yang sebaiknya diambil untuk memperbaiki angkutan umum adalah perbaikan manajemen, yang merubah sistem yang ada saat ini (sistem setoran) menjadi sistem buy the service. Dengan cara ini, maka standar minimum pelayanan angkutan umum akan terjamin, termasuk keandalannya (reliability), yaitu ketepatan jadual dan trayek, serta keamanannya. Dalam perubahan tersebut, dianjurkan sedapat mungkin dapat mengikut sertakan para crew yang lama, termasuk para pelaku informal dari bisnis angkutan umum tersebut. 
Perencanaan Angkutan Umum Perkotaan Yang Berkelanjutan; Ahmad Munawar

Untuk kota besar dan medium seperti Jakarta, Bandung, Surabaya, Medan, Semarang dan Yogyakarta, sistem angkutan umum massal sudah harus dipikirkan untuk jangka menengah/panjang. Sistem angkutan umum massal dapat berupa sistem jaringan jalan rel ataupun jalur khusus bus.

\section{Daftar Pustaka}

Abubakar, Iskandar, Mass Transit as a Possible Mode for Sustainable City Development, Paper at Sured $1^{\text {st }}$ Yogyakarta: Seminar UGM,Maret 2000

Departemen Perhubungan, Direktorat Jenderal Perhubungan Darat, Kebijakan Transportasi Perkotaan di Indonesia, Jakarta, Mei, 1999
Magister Sistem dan Teknik Transportasi UGM, Perubahan Jalur Angkutan Umum Perkotaan Terhadap Beroperasinya Terminal Giwangan, Laporan Akhir, Oktober, 2004

Magister Sistem dan Teknik Transportasi UGM, Studi Kelayakan Reformasi Sistem Transportasi Angkutan Umum Perkotaan di Propinsi DIY, Laporan Akhir, Desember 2005

Munawar, A., Budi Hartanto, Titi Liliani S. dan Moenadji, Tinjauan Kebijakan Angkutan Umum Perkotaan (Studi Kasus Bandung), makalah pada Seminar Nasional Transportasi di ITB, Bandung, November, 2001 